Cuad. Invest. Filol., 49 (2021), 77-106. http://doi.org/10.18172/cif.4925

\title{
MIGUEL HERNÁNDEZ O LA LLAMADA DE LA SANGRE: DEL DESEO SEXUAL INCONTENIBLE AL IMPULSO ERÓTICO IRREFRENABLE
}

\author{
Víctor Cantero García \\ Universidad Pablo Olavide \\ cantero91@hotmail.com
}

\begin{abstract}
RESUMEN: Mucho se ha especulado sobre el influjo que las experiencias amorosas de Miguel Hernández pudieron tener en la composición de sus poemas. Sin embargo, poco se ha explicado el alcance y la repercusión de las mismas en la construcción de su equilibrio emocional y en la plena satisfacción de sus deseos sexuales y sus impulsos eróticos. Este es el objeto de la presente contribución: ¿logró Miguel Hernández realizarse sexualmente en las relaciones amorosas que mantuvo con Josefina Manresa, Maruja Mallo y Maria Cegarra o más bien dichas relaciones le dejaron insatisfecho sexualmente y emocionalmente decepcionado?

Mediante un análisis testimonial contrastivo ponemos de manifiesto que con ninguna de las mujeres citadas colmó el poeta oriolano sus deseos sexuales, a través de la entrega incondicional, en lo fisico y en lo espiritual, por parte de ambos amantes. De aqui que el sinsabor y la decepción mantuvieran abierta la "herida del amor" hasta el final de sus dias.

PALABRAS CLAVE: sexualidad, eros, pasión, insatisfacción, Miguel Hernández.
\end{abstract}

\section{MIGUEL HERNÁNDEZ OR THE CALL OF THE BLOOD: FROM IRREPRESSIBLE SEXUAL DESIRE TO UNSTOPPABLE EROTIC IMPULSE}

ABSTRACT: Much has been especulated about the infuence that Miguel Hernández's love experiences could have on the composition of his poems. However, little has been explained the scope and impact of the same in the construction of his emotional balance and in the full satisfaction of his sexual desires and his erotic impulses as a man: did Miguel Hernández achieve sexual fulfillment in his love relationships he had with Josefina Manresa, Maruja Mallo and Maria Cegarra, 
ore rather did these relationships leave him sexually dissafected and emotionally disappointed?

By means of a contrastive testimonial analysis we show that with none of the women mentioned did the Oriolan poet fulfill his sexual desiresm trough the unconditional dedication, in the physical and the spiritual by boht lovers. Hence the unpleasantness and disappointment kept open on his soul the "wound of love" until the end of his days.

KEYWORDS: Sexuality, eros, passion, dissatisfaction, Miguel Hernández.

\title{
MIGUEL HERNÁNDEZ OU L'APPEL DU SANG: DU DÉSIRE SEXUEL IRRÉPRESSIBLE À L'IMPULSION ÉROTIQUE INARRETTABLE
}

\begin{abstract}
RÉSUMÉ: On a beaucoup spéculé sur l'influence que les expériences amoureuses de Miguel Hernández pourraient avoir sur la composition de ses poèmes. Cependant, on a peu expliqué la portée et la répercussion de la même chose dans la construction de son équilibre émotionnel et dans la pleine satisfaction de ses désirs sexuels et de ses pulsions érotiques en tant qu'homme. C'est le but de cette contribution: Miguel Hernández a-t-il atteint un épanouissement sexuel dans les relations amoureuses qu'il a eues avec Josefina Manresa, Maruja Mallo et María Cegarra, ou plutôt ces relations l'ont-ils laissé sexuellement insatisfait et émotionnellement déçu?

À travers une analyse de témoignages contrastés, nous montrons qu'avec aucune des femmes citées, le poète orien n'a réalisé ses désirs sexuels, par le dévouement inconditionnel dans le physique et dans le spirituel des deux amants. D'où la déception et la déception conservé ouvre dans son âme la «blessure de l'amour» jusqu'à la fin de ses jours.
\end{abstract}

MOTS CLÉS: sexualité, eros, passion, insatisfaction, Miguel Hernández.

Recibido: 07/11/2020. Aceptado: 27/05/2021

\section{Introducción}

Siendo el propósito del presente estudio demostrar que de las tres consabidas heridas que constituyen el eje del poema [25] de Cancionero y romancero de 
ausencias, (1958) 1“la del amor” fue la que jamás cicatrizó en el alma de Miguel Hernández, estimo conveniente realizar una relectura del mismo al objeto de contextualizar adecuadamente lo que con nuestra contribución se pretende:

\author{
Llegó con tres heridas: \\ la del amor, \\ la de la muerte, \\ la de la vida. \\ Con tres heridas viene: \\ la de la vida, \\ la del amor, \\ la de la muerte. \\ Con tres heridas yo: \\ la de la vida, \\ la de la muerte, \\ la del amor. \\ (Hernández 2010: 600)²
}

Si asumimos que el sustantivo "herida" es el hilo conductor que atraviesa todo el poema, acompañado de los tres complementos circunstanciales precedidos de la preposición con: "la del amor", "la de la muerte", "la de la vida", es el orden de la ubicación de los tres motivos de la mencionada "herida" lo que determina tanto la intensidad como la duración de la del amor. De tal modo que:

La primera, la herida del amor, es un tópico barroco (recordemos a Quevedo: "En los
claustros del alma la herida / yace callada; mas consume hambrienta / la vida, que en
mis venas alimenta / llama por las medulas extendida [...]") que ahora se desautomatiza:
si en el barroco la herida de amor consumía al poeta y éste, a la vez, se alimentaba de
ella, de suerte que el poeta gozaba de la herida, ahora la herida de amor se presenta
vinculada a la de la muerte y a la de la vida, una vinculación que se establece mediante la
enumeración y mediante el hecho de que amor, muerte y vida ocupen siempre las mismas

1. Fecha de la primera edición, en Buenos Aires: Lautaro.

2. Para las citas y referencias a los textos de Miguel Hernández seguimos la siguiente edición de sus obras: Miguel Hernández. Obra Completa (2010), Madrid: Espasa Clásicos. Ello siempre que los textos citados se recojan en la misma. 
Es decir, que de las tres heridas, la más significativa es la del amor, no solo porque en la última estrofa cuente con el sujeto en primera persona "yo", como persona que sufre las tres heridas, frente a la impersonalidad del "llegó" y el "viene", sino porque la posición que ocupa "la del amor" en el poema es determinante: es la primera herida que se menciona en la primera estrofa y la tercera en la última, por lo que es la herida que abre y cierra el poema. Este orden desmonta otro de los tópicos barrocos, el del "amor constante más allá de la muerte", dando lugar a otra formulación del mismo: "la herida de amor más allá de la muerte". Según lo cual no es el amor el que permanece más allá de a muerte, sino la herida provocada por el mismo.

Esto es lo sustancial de nuestro empeño, a saber: demostrar que la "herida del amor" nunca cicatrizó en el alma de Miguel Hernández, toda vez que ni su incontenible deseo sexual, ni su irrefrenable impulso erótico lograron verse plenamente satisfechos a lo largo de sus años de vida, por lo que la referida herida le acompañó más allá de la muerte. Lo que dicho con otras palabras equivale a afirmar que si para el poeta la praxis del amor implicaba la ejercitación del sexo con la mujer amada, merced a la entrega incondicional de los amantes a la causa del amor, dicha praxis nunca se desarrolló tal como él deseaba. En cierto modo, esto es lo que se desprende del poema arriba citado, el cual forma parte de Cancionero $y$ romancero de ausencias que es una especie de testamento a modo de sumario vital. Un testamento en el que la poesía hernandiana alcanza el cénit de su lirismo y el punto más álgido en su empeño por trasladar al lenguaje poético la quintaesencia de sus sentimientos más profundos. Nos referimos a un poemario que es fruto de la honda meditación acerca de todo aquello que le ha dejado huella a lo largo de su vida. De aquí que al final de la misma se empeñe en dejar constancia del intenso dolor que le ha provocado la «herida del amor», capaz de producir desgarro incluso más allá de la muerte. Y ¿cuál es la causa de tanto dolor? Esta es la cuestión a la que damos respuesta en nuestra aportación, a lo largo de la cual demostraremos que dicho dolor es la consecuencia de lo mucho que Miguel Hernández sufrió debido al alto grado de insatisfacción, al no lograr ni la plena satisfacción de sus deseos sexuales, ni la total consumación de sus impulsos eróticos.

A los efectos de evidenciar el desajuste entre los deseado y lo obtenido, partimos del singular concepto de la sexualidad y de la vivencia de la misma forjado en la mente de nuestro autor desde su infancia y adolescencia. Su permanente 
contacto con el mundo natural y su dedicación al pastoreo, le hicieron descubrir la fuerza y el vigor del deseo sexual como una pulsión biológica primaria que él no estaba dispuesto a reprimir. Desde niño asume que el sexo ha de responder a la llamada de la sangre. Este es el primer asunto al que dedicamos nuestra atención, pues del mismo se desprenden en lógica secuencia de causa-efecto el resto de los contenidos aquí abordados. En segundo lugar procedemos a evidenciar hasta qué punto Hernández se empecinó en que Josefina Manresa, Maruja Mallo y María Cegarra lo amasen y sintiesen deseos sexuales por él, como hombre, con el mismo vigor y la misma pasión con la que él era capaz de entregarse a ellas como amante. Un empecinamiento estéril, pues ninguna de las tres - por las circunstancias que se exponen - entendía las relaciones íntimas de igual modo que el poeta. Para explicar esta desproporción realizamos un recorrido por el itinerario amoroso del poeta a objeto de constatar cómo en ninguna de las tres relaciones de pareja logró nuestro autor el propósito que pretendía. Nos ocupamos en un tercer momento de resaltar cómo los intentos fallidos por conseguir lo esperado en el ámbito del sexo, logran doblegar su voluntad y le hacen acatar el modelo de pareja acuñado por las convenciones sociales como último refugio. Ponemos fin a nuestra exposición con el apartado dedicado a las conclusiones.

\section{De la pulsión sexual como instinto biológico primario al eros: la trasformación de la sexualidad en amor}

Dado que lo que pretendemos es poner de relieve que Miguel Hernández tuvo a lo largo de su vida vivas e intensas pulsiones sexuales, lo primero que procede es demostrar el origen de las mismas. Y lo hacemos con el ánimo de entender mejor cómo el poeta oriolano vivió todo lo relacionado con su sexualidad con una energía vital y con un vigor irreprimibles, los cuales chocan con: "la intensa represión sexual entre su Orihuela natal y la disciplina moralizadora de su novia, Josefina Manresa, en quien Miguel Hernández no llegó nunca encontrar (ni en el matrimonio) su plena expresión sexual" (Acereda 1996: 1). El siguiente comentario de Félix Grande Lara da fe de ello:

Además de meticuloso, Miguel es siempre primitivo y terrícola. La sensualidad, al hijo, al agua, al sol, son los domingos primordiales de calendario de su obra [...] Miguel parte siempre del mundo sensible que configuran las emociones más humanas y terrenales y a ellas regresa tras su viaje por la más ejemplar poesía española y por sus propias dotes de creador ejemplar (Grande Lara 1991: 12-13) 
Y nos pone sobre la pista de nuestro objetivo: la estrecha relación del poeta con las emociones que emanan de lo terreno y de lo carnal. Por ello, no resulta extraño que Hernández se sintiera: "preso de un fatum —un "Sino sangriento"en la medida en que no pudo llevar a la realidad su deseo. Desde su infancia se insatisfizo: tuvo cabras en vez de libros, gritos en lugar de afectos y tradujo este ananké como un destino incumplido o adverso, causante de la ira" (Gracia 2020). Es justo en ese marco natural, rural y ganadero donde Miguel Hernández -al igual que le ocurriera a Félix Grande Lara, quien relata en Mayoral que no cesa su experiencia como pastor en claro parangón con la del poeta- presenció en múltiples ocasiones a las: "cabras pariendo al caer la tarde, los chotos pugnando por ponerse en pie mientras sus madres les lamían las materias gelatinosas de la placenta" o se percató de que: "el macho era menudo y duro, valiente en las peleas hasta sangrarle la mocha testud, increíblemente viril en época de celo, con un olor a semental que llenaba las cuadras como llena la alacena el olor del membrillo" (Grande Lara 2016: 19-20). Y la prueba evidente de que nuestro poeta vivió una experiencia similar la tenemos en su poema Aprendiz de chivo, en el cual verbaliza con total nitidez y naturalidad el más primitivo instinto de esa tierna criatura, la cual no se conforma con buscar el alimento de su madre:

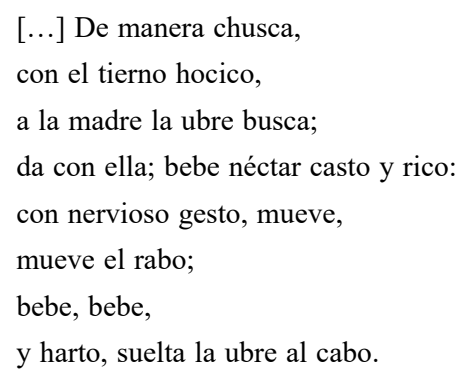

Sino que una vez amantado: "se siente poderoso/ ya no gime ni solloza", al contario:

se alza jubiloso,

victorioso; ya rebulle; ya retoza.

$\mathrm{Y}$ en el gozo que le enciende,

ya pretende,

a la cabra que lo ha dado, penetrar puesto en dos patas".

(Hernández 2010: 61) 
Una fuerza instintiva que se traduce en el ardiente deseo del "aprendiz de chivo" por iniciarse lo antes posible en las prácticas sexuales propias del apareamiento, ya que su instinto sexual es un factor genético que es incapaz de frenar. Esta vivencia del ardor sexual en mundo animal despertó la libido de Miguel Hernández y le ayudó a comprender que su condición sexual como hombre no alcanzaría su pleno sentido hasta que no lograse la plena satisfacción de sus deseos en el ámbito del sexo. En tal sentido podemos afirmar con Agustín Sánchez Vidal que: "el impulso que guía su obra incipiente procede del oficio de pastor, a partir de los catorce años, cuando su padre le obliga a dejar la escuela y lo pone a cuidar el rebaño familiar" (Sánchez Vidal 2010: 29)

Sin embargo, la satisfacción del deseo sexual no obedece en Miguel Hernández al innato deseo de dar respuesta a la llamada de la sangre mediante la cópula, sino que nuestro autor distingue entre la "energía sexual" entendida como una vibración baja y densa, relacionada con la función de la reproducción: la preservación de la especie mediante la multiplicación a nivel biológico, y la "energía erótica" asumida como una vibración alta, pura frecuencia divina, que se amalgama con la energía del amor sublime y divino. Miguel Hernández admite que el sexo por sí mismo tan solo produce separación, pues une a dos prisioneros, a dos egos aislados, mientras que entiende el amor como un estado de profunda comunión entre dos almas, siendo el eros la escalera que conecta a ambas. Una escala cuyo extremo inferior está fijado al suelo de la sexualidad y el extremo superior alcanza a la divinidad. Es decir, el poeta asume la sexualidad como un impulso erótico, como la exacerbación del deseo sexual por medio de la imaginación, la fantasía o la estimulación sensorial provocada por el placer sexual. Miguel Hernández vive el erotismo como una expansión de la dimensión simbólica y afectiva de la sexualidad, ya que para él el sexo pertenece al universo simbólico, afectivo o psicológico y la sexualidad cumple una función psíquicoafectiva.

Por ello, en el verso hernandiano, tal como ocurre en los poetas surrealistas, se produce la identificación del amor y el sexo. Así lo podemos apreciar en la Octava XVI de Perito en Lunas:

(SERPIENTE)

En tu angosto silbo está tu quid,

$\mathrm{y}$, cohete, te elevas o te abates ;

de la arena, del sol con más quilates, 


\begin{abstract}
lógica consecuencia de la vid,
Por mi dicha, a mi madre, con tu ardid, en humanos hiciste entrar combates.

Dame, aunque se horroricen los gitanos, veneno activo el más, de los manzanos.

(Hernández 2010: 190)
\end{abstract}

En este poema Hernández recurre a la serpiente como claro símbolo fálico "que te elevas y te abates" con clara voluntad de restablecer el equilibrio perdido en el doble movimiento de ascenso y descenso que conlleva en el hombre el acto sexual. De un lado, remonta hacia arriba para captar el deseo desde sus comienzos, y de otro, desciende hasta la profundidad para lograr la total penetración. Un movimiento que traduce el impulso expansivo de lo erótico como fuerza vital en Miguel Hernández, el cual manifiesta su sed erótica como un deseo que pretende ver satisfecho. El poeta reitera la simbología sexual de la serpiente en los versos 5 y 6 , pues gracias a la "relación humana" entre sus progenitores fue él felizmente engendrando. En suma, mediante una técnica preciosista, nuestro autor elabora un juego de factura típicamente gongorina, en base a un lenguaje en el que el valor connotativo de los vocablos tiene mayor relevancia que el conceptual. En el trasfondo de dicho lenguaje se esconde el anhelo insofocable de Miguel Hernández por ver satisfecho su deseo sexual mediante el encuentro íntimo con la mujer amada, el cual ha de mantener el vigor de su impulso erótico. Una prueba evidente de este nexo entre sexualidad y poesía la encontramos en su poema Canción del esposo soldado, de Vientos del pueblo (1937) en el que lo seminal se afirma con honda raíz erótica, como superación de un tiempo escindido. En sus versos la sacralidad inherente al acto de creación se transfiere a la semilla sobre el campo. El primer cuarteto es la antesala del auténtico recital que viene después, en el cual el poeta despliega todas sus ansias de culminación del deseo sexual transformado en eros con una claridad irrepetible:

He poblado tu vientre de amor y sementera,

He prolongado el eco de sangre a que respondo

Y espero sobre el surco como el arado espera:

He llegado hasta el fondo.

(Hernández, 2010: 512) 
Por medio de metáforas agrícolas, en las que el cuerpo de la amada equivale al campo por arar y sembrar, el poeta en primer lugar prepara el terreno para la "sementera" poblando "tu vientre" de amor, en diáfana alusión al preludio amoroso, el cual prolonga - enciende aún más si cabe - el ardor y el fuego del deseo, la pasión ilimitada que responde al "eco de la sangre". Acabados los preliminares, el arado - símbolo fálico - aguarda "sobre el surco" - labios abiertos del órgano genital femenino - para penetrar "hasta el fondo". Penetración que equipara al coito con el acto de creación poética, pues ambos suponen una penetración el ámbito de lo oscuro.

De similar factura erótica es la Octava XL (Negros ahorcados por violadores) de Perito en lunas, en la cual Hernández no solo usa símbolos referidos a los órganos sexuales, sino que logra hablar directamente del acto sexual, al detallar la violación de una mujer blanca por un norteamericano negro en estos términos:

Su más confusa pierna, por asalto,

Náufraga higuera fue de higos en pelo

Sobre nácar hostil, remo exigente...

¡Norte! Forma de fuga al sur: ¡serpiente!

(Hernández, 2010: 198)

La "náufraga higuera" y el "remo exigente" son los testículos y el pene, el cual ha penetrado el "nácar hostil", entendido como el órgano sexual femenino que "hostil" repele la violación. Los "higos en pelo" son los testículos desnudos que le cuelgan al violador. Tal como precisa Aggor Francis Komla:

Sánchez Vidal facilita la comprensión de estos versos. La negrura de los violadores está representada por la de los "higos" que contrastan con la blancura del cuerpo femenino. La aparición sorprendente de la serpiente al final de la octava, entrecalada entre los signos admirativos tiene tres posibilidades de interpretación: puede ser el órgano sexual masculino o el movimiento ascendente-descendente del violador o puede equiparar la lujuria de la serpiente a la crueldad de la violación (Komla Aggor, 1976: 98)

Situación que se repite en la Octava XI (Sexo instante, 2) en la que de nuevo se hace alusión a los términos higuera e higos: 
¡Al polo norte del limón amargo

desde tu arena azul, cociente higuera!

(Hernández, 2010: 189)

Repetición que abunda la interpretación antes dada sobre dichos vocablos, pues:

La higuera va ligada al sexo por multitud de motivos; los higos cerrados semejan los testículos; abiertos, el sexo femenino. Sus hojas sirvieron de primer vestido a la mujer [...] Una parte de la tradición patrística atribuye a la higuera y no al manzano el papel sustentáculo de la serpiente tentadora [...] (Sánchez Vidal, 1976: 98)

En todos estos casos existe un denominador común: que en la poesía de Miguel Hernández el sexo tiene un sustrato que lo vincula de modo constante con el eros. Dicho sustrato hunde sus raíces en el apetito sexual y en las pasiones carnales, más allá de los "condicionamientos sociales o de las cuestiones ideológicas (sobre todo de signo religioso) que pudieran pesar sobre él en alguna etapa de su vida" (Cuenca Abela, 2015: 8). Estos ejemplos nos permiten afirmar que:

\footnotetext{
Miguel Hernández fue un poeta de verbo compulsivo. Lo orgiástico de su verso lo condujo catárticamente hacia la — que hubiese deseado - ataraxia final. No es un poeta reflexivo, sino intuitivo. No es un autor que se pregunte por la existencia, sino que responde a su vida. No especula con escaramuzas filosóficas sobre el mundo. Se interesa por lo concreto: por sí mismo. Pero sus emociones son universales. Todo autor desemboca en su obra una carga semántica que explota ante el lector (Gracia, 2000)
}

\section{El periplo amatorio de Miguel Hernández: del goce sexual deseado al calvario padecido}

Una vez comprobado que la carga pasional con la que Miguel Hernández vive su deseo sexual responde a sus pulsiones eróticas emanadas de su instinto biológico, procede demostrar hasta qué punto nuestro poeta fue capaz de satisfacer dichas pulsiones a través las relaciones íntimas que mantuvo con las tres mujeres que jalonan su itinerario amatorio: Josefina Manresa, Maruja Mallo y María Cegarra. Para dar una respuesta bien fundamentada a esta cuestión realizamos un análisis testimonial contrastivo basado en los argumentos expuestos por dichas mujeres y la réplica que Hernández hace a los mismos. De esta confrontación se 
deduce que ninguna de ellas fue capaz de colmar su apetito sexual y sus fantasías eróticas. En tal sentido su "herida del amor" permaneció abierta hasta sus días postreros, toda vez que ninguna de sus amadas correspondió a sus ardientes deseos, a su entrega pasional al ser amado, en la misma medida que él lo hizo.

Resulta a todas luces evidente que el noviazgo de Miguel Hernández con Josefina Manresa no traspasa el umbral del canon tradicional. Hablamos de un amor adolescente, que llegada la juventud no puede ir más allá de la conversación tras la reja, pues ambos viven su amor en la asfixiante atmósfera de una sociedad oriolana sometida a las estrictas pautas morales de la imperante doctrina católica. En este contexto hay que ubicar el ritual de cortejo, tal como lo refiere la propia Josefina: "Miguel me estuvo pretendiendo desde el año 1933, verano, hasta septiembre de 1934. Pasaba varias veces por la puerta del taller de la Calle Mayor, en Orihuela, donde yo trabajaba como modista" (Manresa, 1980: 1). Todo encaja en ella con el perfil de una joven educada en los principios morales y en la austeridad propia de la familia de un guardia civil de segunda clase. Por ello, Josefina responde al patrón de una muchacha trabajadora, educada, recatada y sumisa al estatus moral dominante, la cual jamás pensó en dejar su pueblo natal para abrir su mente a nuevos mundos En el extremo opuesto tenemos a Miguel Hernández, quien el 30 de noviembre de 1930 realiza su primer viaje a Madrid y en febrero de 1935 ya se había asentado en la capital, animado por Pablo Neruda. Durante estos cuatro años el poeta ha tenido tiempo suficiente para dejar atrás la estrechez mental propia del provincianismo oriolano y adoptar una mentalidad tolerante y abierta ante las nuevas realidades y los nuevos tiempos propios del Madrid del momento. En este contexto es en el que hemos de entender los reproches que le hace a Josefina en carta del 27 de julio de 1935 , censurando su incapacidad de darle un beso en cualquier espacio público sin pensar antes en el qué dirán de la gente. En dicho reproche va implícita una queja, pues su novia no muestra la misma apetencia erótico-sexual que él siente hacia ella. En clara sintonía con estas recriminaciones, Miguel Hernández expresa su pleno desacuerdo con el proceder amoroso de Josefina en los sonetos 4 y 11 de El rayo que no cesa, de los que reproducimos los primeros cuartetos:

Me tiraste un limón, y tan amargo, con una mano cálida y tan pura, que no menoscabó su arquitectura y probé su amargura sin embargo. (Hernández, 2010: 421) 
Te me mueres de casta y de sencilla: estoy convicto, de amor, estoy confeso de que, raptor intrépido de un beso, yo te libé la flor de la mejilla.

(Hernández, 2010: 424)

Ya no es tan solo que ambos se encuentren a leguas de distancia en cuanto al deseo de la carne, sino que el recato de su novia es tal que ni se atreve a darle un beso con plena libertad:

Pero tú eres muy vergonzosa, no te gusta que te vean quererme, y a mí me importa un pito, por no decir otra palabra más expresiva que pito, casi igual en vez de t lleva j. ¿Si nos han hecho para eso, por qué vamos a ocultarnos cuando nos tenemos que hacer una caricia? (Hernández, 2010: 1542)

Con este precedente no es de extrañar que Miguel Hernández, introducido en los círculos culturales e intelectuales madrileños, así como en las tertulias literarias de la capital, pusiera sus ojos en otras mujeres. Tal es el caso de María Zambrano:

Filósofa y pensadora veleña, seis años mayor que él. La conoció en el tercer viaje a Madrid (fotografía de grupo en el homenaje dedicado Vicente Aleixandre en junio de 1935 donde aparece Miguel y María). Sin embargo, creo que María no era una mujer destinada para Miguel por la diferente formación intelectual existente entre ambos, sino más bien, era una amistad pura y verdadera, una relación literaria. (Fernández Palmeral, 2004)

O el de la argentina Delia del Carril, compañera de Pablo Neruda, o María Teresa León, esposa de Rafael Alberti, la cual pese a la desafortunada intervención de Hernández en la sede de la Alianza de Mujeres Antifascistas - con motivo del homenaje que ella había organizado en febrero de 1939 para reconocer la labor de este colectivo femenino en pro de la causa republicana -, nunca dejó de estimar al poeta, a quien consideraba una criatura admirable e inteligente:

Miguel se dirigió entonces visiblemente irritado a Rafael Alberti, con Antonio Aparicio como testigo, y le lanzó la frase: "Aquí hay mucha puta y mucho hijo de puta". El autor de Sobre los ángeles le instó a repetir esas palabras en voz alta y delante de los otros compañeros de la Alianza. Ante el desafío, el poeta oriolano se aproximó a una pizarra que colgaba de una 
de las paredes de aquella dependencia y reprodujo la frase con amplios caracteres. Antes de que Miguel abandonara la sede, María Teresa León vio y leyó el insulto, se sintió aludida, pues ella se había encargado personalmente de organizar aquel banquete de homenaje, y se fue en busca de Miguel. La respuesta de la autora de Memoria de la melancolía fue una enérgica bofetada que, al parecer, hizo caer al poeta (Ferris, 2017)

Sin embargo, pese a las evidentes discrepancias entre Miguel y Josefina en el modo de sentir y expresar sus vivencias y deseos como pareja, el poeta no comienza a plantearse una posible ruptura con su novia hasta encontrarse plenamente ubicado en Madrid en la primavera de 1935. De regreso de su colaboración en las Misiones Pedagógicas recibe la grata noticia de que José María de Cossío le ofrece trabajo como secretario particular al objeto de colaborar con él en la redacción del último tomo de la enciclopedia Los Toros, dirigida por José Ortega y Gasset. Es en este momento cuando se produce una lenta pero imparable transformación ideológica en el poeta. Deja atrás las obsesiones católicas de la etapa oriolana y se siente un hombre libre, con voz propia entre los intelectuales y artistas que pululan por el Madrid de la época. Y es:

Este proceso de transformación ideológica que está sufriendo Miguel el que conlleva al mismo tiempo un replanteamiento de su relación con Josefina Manresa. Lo que en ella veía como virtud, como cualidades necesarias - su religiosidad, su castidad y su puritanismo- se vuelven poco a poco contra él, que ha abierto los ojos a una realidad muy distinta que le lleva a reconocer el retroceso de esas costumbres de las que ha sido víctima y que ella, su novia, encarna todavía. Un simple examen de conciencia le hace comprender que lo único que le une a esa muchacha es la vieja inocencia de antes. Por lo demás, el poeta sabe que Josefina está muy lejos de su mundo, y que su capacidad y voluntad para aceptarlo como es, para entender y compartir con él la aventura de la poesía es un reto imposible (Ferris, 2004: 52)

Tan notables son las diferencias que en carta de primeros de julio de 1935, tras cinco meses sin pisar Orihuela, el poeta le dice a su novia lo siguiente:

Ni yo puedo verte a ti ni tú a mí, y perdemos el tiempo inútilmente con cartas que no sirven más que para desesperarte a ti y a mí, porque me hacen pensar en las horas pasadas ahí. Yo quisiera, Josefina, que no sufrieras tanto por mí, que te olvidaras un poquito de mí: no creo que te sea difícil. Te permito hasta que se te arrime alguien; de lo contrario veo que vas a sufrir mucho, porque vas a estar sola mientras yo no vaya, que Dios sabe cuándo será (Hernández, 2010: 1537) 
Una declaración de ruptura en toda regla, que vuelve a expresar en su carta del 13 de julio de 1935. En este momento cuando se consuma la ruptura de la pareja, que no vuelve a retomar la relación hasta siete meses después, en concreto el 4 de febrero de 1936. Ruptura que es la lógica consecuencia de la total imposibilidad de Miguel Hernández de mantener con Josefina un noviazgo a distancia, el cual para nada satisface sus apetencias sexuales, toda vez que en los ambientes en los que ahora se mueve el poeta puede hallar una mujer mucho más dispuesta y receptiva a dar respuesta a la "llamada de la sangre". Es decir, que por mucho que Josefina: "quiso ser siempre el único amor de Miguel. Tajantemente no lo fue [...] De aquí que se declarara enemiga total mía, por la publicidad que yo daba a las relaciones del poeta con María Cegarra, puramente espirituales y la de Maruja, de acentuado carácter sexual" (Pérez Álvarez, 1994: 38)

Sin embargo, por muchas razones que se pretenda esgrimir para justificar esta ruptura, hay una que no deja lugar a la duda: la relación que Miguel Hernández comenzó a tener con la pintora gallega Maruja Mallo a principios de 1935 y que para julio de ese año ya era vox populi y se comentaba en todos los mentideros madrileños, tanto es así que llegó a oídos de Josefina, pues "rumores llegaron a Orihuela de las aventuras amorosas de Miguel Hernández en Madrid" (Fernández Palmeral, 2004). Finiquitado su noviazgo con la joven oriolana, Miguel no ceja en su interés por encontrar la mujer que responda a sus deseos sexuales y a su vigor erótico. Por ello, cuando en febrero de 1935 tuvo la ocasión de conocer a Maruja Mallo en casa de Pablo Neruda, pensó que al fin su sueño se haría realidad. Y motivos para ello no le faltaban, pues su relación con la pintora gallega fue tan intensa y pasional que hacía presumir que sus pretensiones iban bien encaminadas, máxime cuando: "según afirman testigos de la época, Maruja Mallo fue la primera mujer que cató a Miguel" (Sánchez Vidal, 1992: 135). Tan pronto hubo probado el poeta el gozo y la satisfacción que le reportaban aquellos encuentros sexuales plenos, libres y consentidos, sus impulsos eróticos alcanzaron cotas que él hacía tiempo deseaba. Y ello porque Maruja Mallo reunía todas las condiciones para entablar con ella una relación de pareja intensa y placentera, pues el poeta ve en ella a la mujer que se ajusta:

Al perfil exacto de una mujer desinhibida, libre, alocada, dispuesta a infringir cualquier ley que se interponga entre ella y sus deseos [...] Ella le ha dado la dimensión de varón que tanto ansiaba, la condición masculina plena tras consumar el rito amoroso - "mi voz a su tacto se afemina"- en medio de los campos exultantes de cosechas (Ferris, 2004: 240-241) 
Conocidos los pormenores de la toma de contacto entre Miguel y Maruja, vamos a verificar los derroteros por los que discurrió esta relación, así como las causas que pusieron fin a la misma. A margen de que las circunstancias en que se conocieron nada tiene que ver con el marco local y reducido de su noviazgo con Josefina, lo cierto es que la atracción mutua fue tan intensa que Miguel Hernández dedica a Maruja Mallo muchas de las composiciones de El rayo que no cesa, entre las que destaca como emblemática por su erotismo la siguiente:

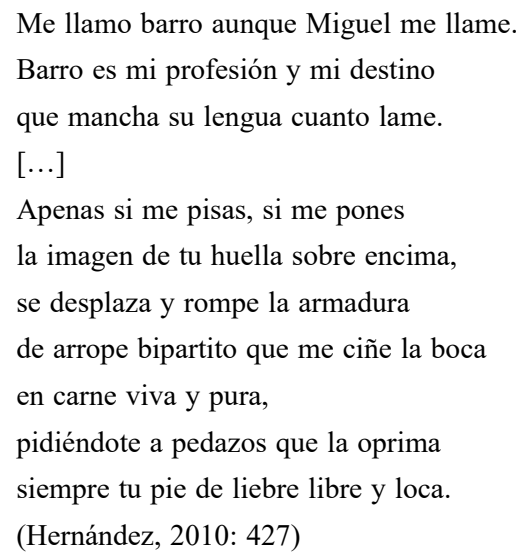

Erotismo que se palpa en la "boca en carne viva y pura" del poeta que ansía besar con pasión a la amada, pero que en su ausencia tiene que conformarse con suplicar que esta le pise con su "pie de liebre libre y loca", en clara alusión al comportamiento amoroso de Maruja, la cual vive su amor con Hernández sin compromiso ni atadura de ningún tipo. Aquí vemos cómo el amor para Miguel es pasión atormentada y ansias de posesión frustradas. La voz herida del enamorado se tiñe de tragicismo y el motivo central es el amor vivido como fatal tortura: el descubrimiento de la pasión amorosa encendida y dolorosa pero imposible con Maruja Mallo. Estos versos dejan bien a las claras lo que a nadie se le oculta, que: "en la poesía hernandiana se reelabora no poca peripecia vivida, y entiendo que así pudo ocurrir en «Me llamo barro...», cuya dialéctica erótica no me hace pensar ni en Josefina Manresa ni en María Cegarra, sino en Maruja Mallo" (Balcells, 2002: 169).

No obstante no hemos de pensar que lo que Miguel Hernández sintió por Maruja Mallo se redujo al deseo de satisfacer su apetito sexual, sino que entre ambos saltó la chispa de la seducción y la atracción fue mutua, pues: 
Ella es pintora, ilustra la Revista de Occidente, ha pintado decoraciones del teatro de Rafael Alberti y presentado cuadros en una sala de París. Ha habido un recíproco deslumbramiento, él por encontrarla encantadora dentro de su arte y su simpatía y ella por parecerle digno de enamoramiento el muchacho rústico que escribe buena auténtica poesía [...] (Ifach, 1982: 58)

Conjeturas aparte, lo que resulta cierto es que la atracción intelectual y espiritual no se habría producido sin el hechizo propio de la seducción. Y buena prueba de ello la encontramos en el siguiente testimonio muy clarificador, aportado por Camilo José Cela:

\footnotetext{
Con algunos amigos literarios me iba a bañar los domingos a La Poveda, en el río Henares, cuando venía el buen tiempo; salíamos de la estación del Niño Jesús y al pasar por los viñedos de Coslada nos bajábamos del tren, robábamos unos racimos de uva, corríamos un poco y volvíamos a bordo de un brinco y ayudados por los viajeros que iban en la última plataforma: al llegar a San Fernando el tren cambiaba de máquina, le ponían una más lenta y que pesaba menos porque el puente no brindaba muchas garantías de seguridad. Miguel Hernández y Maruja Mallo tenían amores e iban a meterse mano y a hacer lo que podían debajo del puente (...) (Cela, 2001: 178-179)
}

Pasión amorosa la hubo y mucha, y este idilio se repitió en diversas ocasiones, pues tal como apunta la propia pintora en relación con las escapadas realizadas con el poeta: "nos fuimos Miguel y yo a recorrer un camino de la zona triguera entre Perales y Morata de Tajuña. Era magnífico el rito pánico de las eras en verano. Hoz, trigo, hombres sumergidos en oro rojo" (Mallo, 1980). Testimonio que evidencia que ambos viajaron y que pasaron días enteros en plena naturaleza, al amparo de la luna. Experiencias que calaron con profundidad en el ánimo de Miguel Hernández, tal como se nos muestra en el siguiente soneto de Imagen de tu huella - del que reproducimos los dos cuartetos - dedicado a Maruja, el cual es un vivo reflejo de la intensidad erótica y el deseo carnal con el que vivió su amor con la pintora:

\footnotetext{
Ya se desembaraza y se desmembra el angélico lirio de la cumbre, y al desembarazarse da un relumbre que de un puro relámpago me siembra.
} 
Es el tiempo del macho y de la hembra, y una necesidad, no una costumbre, besar, amaren medio de esta lumbre que el destino decide de la siembra, (Hernández, 2010: 414-415)

Una vivencia del amor en pareja profunda y entrañable, a la cual la pintora alude en el siguiente comentario:

\begin{abstract}
Proseguimos nuestro viaje, unos campesinos que cruzaban repletos de estallantes espigas nos informaron que estábamos próximos a Morata de Tajuña [...] Al entrar en el camión, los campesinos nos entregaron un ramo de flores, pidiéndonos disculpas por el alojamiento que nos brindaba...yo recordé la frase del Conde de Keyserling, cuando manifestó que la aristocracia en España está en el pueblo (Mallo, 1979: 5)
\end{abstract}

Esta estrecha relación interpersonal propició el mutuo influjo que ambos experimentan en sus respectivos quehaceres artísticos. Ambos participan de los principios estéticos de la Escuela de Vallecas, por lo que parece claro que:

Miguel halló en los cuadros de la serie Cloacas y campanarios elementos de suficiente interés como para asumirlos en su obra lírica, siempre en evolución, en pleno proceso, y fundir los iconos representados por la pintora con los poemas que ella misma le hubo de inspirar en el terreno afectivo. Obras como "Huella de esqueleto", "Antro de fósiles" o la repetida representación de los campanarios, edificaciones tenebrosas azotadas por el temporal y el rayo que encierran un descarado anticlericalismo, tienen su espacio en múltiples poemas de El rayo que no cesa (Ferris, 2004: 55)

Hasta tal punto Hernández asumió que aquella relación iba por el buen camino que jamás sospechó que tenía los días contados. El poeta se entregó por completo a la pintora sin percatarse de que ella tan solo lo amaba como a uno de los muchos hombres que pasaron por su vida: sin ningún compromiso ni atadura por su parte. Entre dichos amores pasajeros se encuentran el escultor Emilio Alafren o el mismo Rafael Alberti, antes de que conociera a María Teresa León. Maruja es una mujer admirada y deseada por muchos pretendientes, pero jamás se quedó con ninguno, y Miguel no iba a ser una excepción. Por ello, cuando a posteriori se le preguntó a la pintora por sus amores con el poeta, no tuvo recato en contestar: "yo he jodido tanto y he conocido a tanta gente que se 
me amontonan un poco en la memoria" (Mallo, 1989). En suma, hablamos de una relación que supuso mucho más para el poeta que para la pintora, pues con ella Miguel Hernández no solo se inició en la práctica satisfactoria del sexo, sino que desarrolló sus anhelos eróticos tal como deseaba. En pocos meses ha pasado de un extremo a otro, de la recatada y tímida Josefina a la pasional y alocada Maruja. Si con la primera cosechó un desengaño, lo que le proporcionó la segunda fue una enorme decepción. Su ruptura con la pintora fue mucho más dolorosa, pues tan solo de pensar que para ella había sido un capricho pasajero, un juguete del que se aprovechó por su inocencia e inexperiencia en las prácticas sexuales, le causó una profunda amargura.

Sin embargo, Hernández asume el fracaso y no declina en su afán por lograr el amor de la mujer que se ajuste a sus deseos. En su momento aceptó que con Josefina no podía ser feliz y fue él quien puso final al noviazgo. Por el contrario, ahora es él quien ha sido dejado por Maruja, por lo que se siente mucho más dolido. Pero ni en el primer caso ni en el segundo se achanta, sino que demuestra su entereza como hombre capaz de asumir sus fracasos amorosos y se abre a nuevas posibilidades. Y es el azar quien le da la oportunidad de conocer a María Cegarra Salcedo: la tercera mujer que compone el trío de su periplo amoroso. Nos consta que a fecha de 13 de julio de 1935 rompió con Josefina; pues bien, a mediados de ese mismo año Miguel escribe a sus amigos Carmen Conde y Antonio Oliver Belmás para agradecerles la acogida que le habían dispensado con motivo de su asistencia a los actos que ambos habían organizado en nombre de la Universidad Popular de Cartagena por el tricentenario de Lope de Vega. Actos en los que el poeta intervino con la conferencia titulada Lope de Vega en relación con los poetas de hoy, pronunciada el 27 de agosto. $\mathrm{Y}$ esta misma carta ya manifiesta su interés por María Cegarra:

Estoy aquí y ya no sé si he estado ahí, con vosotros, con los molinos, con el mar y las islas, con María [...] Quiero escribir pronto a María: sé que le haría un bien grandísimo salir de su ambiente mineral y familiar. Comprendo su drama, y sería triste verla envejecer sola en la Unión (Hernández, 2010: 1546-1547)

Un interés que se despertó con ocasión de las conversaciones que ambos mantuvieron durante las excursiones que hicieron al Cabo de Palos con Carmen y Antonio y otros amigos, los días 26 y 27 de agosto de 1935. Tan solo una semana después de su regreso a Madrid, Hernández no puede reprimir por más tiempo sus ganas por tener a María Cegarra a su lado y el 7 de septiembre le escribe en estos términos: 
Querida amiga María:

No puedes imaginarte cuánto pienso en tu persona desde nuestro encuentro en tu pueblo.

Qué poco nos hemos tratado, ¿no te parece? Te conocí de pronto en Orihuela, te hablé unos momentos; te vi en Cartagena después otros instantes y, por fin, este agosto pasado, inolvidables para mí los días que estuve por esas tierras. Logré hablarte durante varias horas [...] ¿Cuándo vendrás a Madrid? Quiero que te conozcan mis amigos mucho. He hablado de ti a Neruda, hablaré a Vicente Aleixandre y a quien a mí más me interesa poéticamente [...] (Hernández, 2010: 1547-1548) ${ }^{3}$

Queda claro que a Miguel Hernández no se le va de la cabeza la imagen de aquella joven en la que había puesto de nuevo sus esperanzas para lograr lo que no consiguiera ni con Josefina ni con Maruja. Tras su fracaso con la pintora gallega, el poeta había aprendido que evidenciar sus deseos sexuales y dar a entender su ardor pasional no era la técnica de seducción más eficaz. En sus horas de conversación con María comprendió que la joven era mujer de otra hechura, y lo que primero debía lograr de ella era una sana amistad, dejando a un lado los impulsos de la carne. Ella era una muchacha sin sofisticaciones ni vanidad alguna y mucho menos con interés por aventuras amorosas pasajeras. Era una mujer centrada en sus quehaceres profesionales - profesora de Química en la Escuela de Peritos Industriales y Maestría y en Centros de Formación Profesional y Bachillerato -, así como en sus obligaciones familiares, pues era ella el sostén económico de los suyos, toda vez que la crisis económica azotase con fuerza en aquellos años la cuenca minera de La Unión.

3. Esta es la primera de las tres cartas que Miguel Hernández escribe a María Cegarra. Ella no consiente en que se hagan públicas hasta después de su muerte. De ello nos deja constancia en su repuesta al periodista J. García Martínez que la entrevistó para la sección "Domingos", de La Verdad (Murcia) el 18.06.1978: "Guardo tres cartas suyas que yo solo he leído". Se hace preciso aportar algunos detalles esenciales de esta peculiar amistad:

Ambos, Cegarra y Hernández, se conocieron en Orihuela el domingo 2 de octubre de 1932, con motivo de la inauguración del busto dedicado a Gabriel Miró en la Glorieta que desde entonces lleva su nombre. Cegarra acompañó a la delegación procedente de Cartagena, de personas integrantes de la Universidad Popular de Cartagena, dirigida por Antonio Oliver Belmás y Carmen Conde (Larrabide, 2019: 37)

La siguiente ocasión en que vuelve a verse con María nos sitúa en el 29 de julio de 1933. En este caso:

Tras la publicación de Perito en Lunas, en Murcia, al cuidado de Raimundo de los Reyes, volvieron a coincidir Carmen y Antonio con Miguel cuando invitaron a este a que diera un recital de sus poesías en Cartagena, en la Universidad Popular, el día 29 de julio de 1933, tal como anuncia la revista Presencia en su número 2 «Conferencia y recital del poeta levantino Miguel Hernández Giner, el 29 de julio de 1933». Y, en efecto, Miguel Hernández se presentó en la Universidad Popular de Cartagena en verano del 1933 con un cartelón dibujado por el pintor oriolano Francisco Díe y con cierta aparatosidad teatral (Díez de Revenga y De Paco, 2010: 85) 
Descartado el acercamiento por la vía del abordaje erótico-sexual, Hernández recurre a la seducción por la vertiente intelectual. Así, en la carta citada le agradece que le haya mandado un ejemplar del libro de poesía que acaba de publicar en la colección Sudeste con el título Cristales míos (1935). Le pide que le envíe más ejemplares para repartirlos entre sus amistades y hace un elogioso comentario sobre el mismo Valoración de la que se desprende que Miguel ha encontrado en María a su alma gemela, pues ambos respiran por la misma veta lírica. No en vano podemos afirmar que existen elementos comunes entre Cristales míos y Perito en lunas. Tanto es así que:

\begin{abstract}
El término común a ambos libros es «trasmutación», trasmutación de la materia en espíritu, en sentimiento desligado, en deseo etéreo, en tiempo recobrado, en ascensión y comunión con el mar y la luz... La luz, elemento mironiano por antonomasia, une ambos libros. Son libros de una poesía de síntesis, con la palabra precisa que perfila límites a través de metáforas e imágenes (Larrabide, 2019: 40)
\end{abstract}

Esta es la vía de comunión espiritual por la que Miguel intenta ganarse el favor de María, de otro modo no entenderíamos el afán del poeta por agradecer a la poetisa el poema que en su libro le dedica (poema 43), en el cual Miguel está bien identificado por su "curtida la piel, alucinada la mirada verde blanquecina" (Rubio Paredes, 1998: 103). Sin embargo, el mejor testimonio de admiración de María hacia Miguel vendrá mucho más tarde. Tras muchos intentos de los biógrafos del poeta oriolano, al fin de se logró que la primera carta que él le escribió a María el 7 de septiembre de 1935, se hiciera pública en la revista Tránsito, (1979) en portada e interior bajo el título Carta inédita de María Cegarra, la cual incluye el poema Presencia de Miguel, dedicado por Cegarra a Hernández:

\footnotetext{
Nadie

-ni antes ni después de ti-

Supo, sabe

Pronunciar mi nombre

Hacías una creación de la palabra,

Del tono, del sonido, del acento...

Entonces...

Te recuerdo en mi nombre

-aprendo de ti-
} 
Que conmigo inseparable llevo.

Inconsumible, ingrávido.

Sin muerte, sin dolor.

(Cegarra, 1979: 7)

Tanto en Cristales míos como en el poema Presencia de Miguel podemos encontrar: "contenidos, guiños, mensajes implícitos de una mujer que vibraba con la presencia de Miguel Hernández y que le proporcionó alguna de las claves para elaborar El rayo que no cesa" (Gómez Vera, 2005: 302). Sin embargo, esta presencia de Cegarra en el texto hernandiano no implica que ella fuese la única mujer en la que Miguel se inspiró para componerlo. Tal como precisa José María Balcells, pese a ser presentado como un libro inspirado en el amor de una única amada: "son tres las mujeres involucradas en la confección de El rayo que no cesa: Josefina Manresa, María Cegarra y Maruja Mallo" (Balcells, 2009: 153) ${ }^{4} \mathrm{Y}$ de las tres, parece ser que Cegarra no se lleva la mayor parte, pues: "su presencia en El rayo que no cesa no va más allá de una dedicatoria manuscrita a uno de los sonetos más intensos “¿No será este rayo que me habita?” (Vidal Ortuño, 2010: 27). Opinión que es refutada por José Luis Vicente Ferris, el cual sostiene que los sonetos de corte más platónico y petrarquista de El rayo que no cesa están inspirados en la poetisa oriolana. Opiniones discrepantes al margen, lo cierto es que Miguel Hernández un día antes de su intervención en el homenaje a Lope de Vega por el tricentenario de su fallecimiento, en el Ateneo de Cartagena, es decir:

El 26 de agosto, el poeta oriolano regaló a la unionense el original manuscrito en tinta verde del poema hernandiano «No cesará este rayo», fechado ese mismo día (y reproducido en el diario alicantino Información el 26 de marzo de 1978), que llevaba la siguiente dedicatoria efusiva: «Para mi queridísima María Cegarra, con todo el fervor de su Miguel Hernández», así como también le obsequió con un ejemplar de El rayo que no cesa, aparecido en enero de 1936 (Larrabide, 2019: 40)

No resulta casual que Miguel Hernández dedique a María Cegarra el soneto arriba citado, el cual está cargado de simbología erótica, tal como vamos a intentar desvelar:

4. Más información sobre este extremo en Balcells, José María (1995). "De Josefina a María y de María a Maruja” en Homenaje a María Cegarra, Ed. Santiago Delagado. Murcia: Editora Regional Murciana, pp. 173-171. 


\begin{abstract}
¿No cesará este rayo que me habita
el corazón de exasperadas fieras

y de fraguas coléricas y herreras

donde el metal más fresco se marchita?

¿No cesará esta terca estalactita

de cultivar sus duras cabelleras

como espadas y rígidas hogueras

hacia mi corazón que muge y grita?

(Hernández, 2010: 420)
\end{abstract}

En este soneto el rayo es la representación hiriente del deseo sexual que "habita el corazón de exasperadas fieras": que impulsa al poeta a darle rienda suelta, y que al no poder hacerlo "el metal más fresco se marchita": su vigor sexual se apaga. Y es que la "terca estalactita": el pene en medio de "sus duras cabelleras": el bello pubiano, está erecto: "como espada rígida" y su deseo carnal se enciende cada vez más como una "hoguera" y hace que su corazón estalle: "mi corazón muge y grita" de deseo de tener conmigo a la amada.

Este rayo que ni cesa ni se agota:
de mí mismo tomó su procedencia
y ejercita en mí mismo sus furores.

De nuevo el rayo, que es el fuego y quemazón que provoca el deseo sexual insatisfecho, pero no por ello muerto, sino todo lo contrario: "ni cesa ni se agota", pues nace del impulso erótico instintivo del poeta: "de mí mismo tomó su procedencia" y se ensaña con el alma del poeta: "ejercita en mí mismo sus furores".

\footnotetext{
Esta obstinada piedra de mi brota

y sobre mí dirige la insistencia

de sus lluviosos rayos destructores.
}

En el segundo terceto la "obstinada piedra" simboliza el pene que por la dureza del mismo sigue erecto. Un vigor sexual que "de mí brota", porque es condición propia de mi condición biológica innata y que al no poder expresarse en la anhelada relación sexual con la amada, se convierte en una fuerza destructora que se vuelve contra el propio poeta como "lluviosos rayos 
destructores". Tanto impulso erótico y tanto apetito sexual tampoco puedo satisfacerlos con María Cegarra.

Desconocemos las respuestas que María dio a las misivas de Miguel, por lo que hemos de interpretar su contenido a través de las respuestas de su correspondiente. A primeros de octubre de 1935 recibe el poeta respuesta a su primera carta. María le contesta y le envía ejemplares de Cristales míos para que los distribuya entre sus amistades. Se trata de un texto escrito en papel perfumado, lo que levanta el ánimo del poeta y le hace pensar que María no eludía una relación de pareja con él. Hernández contesta a vuelta de correo, pero no obtiene respuesta. Este extremo nos consta por la queja que sobre el silencio de María les hace llegar a Carmen Conde y Antonio Oliver en carta de 18 de octubre de 1935, a la par que también se siente molesto porque sus amigos no contacten con él:

\begin{abstract}
Queridos Carmen y Antonio:
¿Qué os sucede amigos míos? Os escribí hace mucho, a poco de llegar aquí, y desde entonces aguardo lo que no llega vuestro [...] Le escribí a María y no contesta hace mucho. Por lo visto, tampoco tiene interés conmigo. Yo he hecho aquí por ella todo lo que he podido (Hernández, 2010: 1549)
\end{abstract}

Tras lograr que María le conteste, el poeta le replica en un tono sumiso. Elimina cualquier reproche que pueda molestar a Cegarra y le recuerda lo mucho que la tiene presente:

\footnotetext{
Quiero que me perdones lo mucho que tardo en contestarte. No quiero decirte nada para disculparme. Sé que tú comprenderás perfectamente que estar ahí da más tiempo y gana para escribir que estar aquí, y rodeado de cosas, trabajos y cuestiones de vida y muerte como estoy [...] Te recuerdo muchísimo y espero que un día me des la noticia gozosa de que vienes por aquí (Hernández, 1998: 95)
}

Miguel sabe que con María las exigencias y las premuras no conducen a nada, por ello en su carta emplea fórmulas de tratamiento que tienen un carácter más íntimo y un tono más persuasivo: "mi apreciada María". "mi querida María", "te recuerdo muchísimo". Expresiones de afecto que muestran el interés de Miguel por conquistar el corazón de la joven. De nuevo vuelve el silencio por parte de su correspondiente, pero en esta ocasión el poeta no aguanta más y sin recibir respuesta le escribe, a primeros de noviembre, en estos términos: 
Querida María: Ya hace tanto tiempo que no me escribes, que me decido a escribirte yo a ti. No sé los motivos del silencio tuyo. Supongo que serán muchas tus ocupaciones, pues no puedo creer que te hiriera ninguna de las cosas que te decía en mi última carta de hace tiempo. Pienso en ti y te veo tan sola en ese pueblo tristísimo, que me da angustia, María. Por eso me gustaría estar escribiéndote continuamente, cosa que me es imposible hacer por varias razones (Hernández, 1998: 95)

Una vez más Miguel se equivocaba, pues los motivos del silencio de María estaban muy claros. Mientras Hernández sentía por ella una verdadera atracción sexual, María le profesaba gran admiración como poeta, pero no lo deseaba ni pretendía tener con él nada más que una sana amistad. Así se lo expuso la unionense a Juan Guerrero Zamora, en la entrevista que este hizo:

\begin{abstract}
Se maliciaba nuestro propósito y esquivaba, casi coqueta y nonagenaria, nuestros asedios. De mujer a mujer, la mía fue sonsacándole qué menos que un juicio llano. Y, desde su hermosa libertad, arriba en la torre de una juventud prendada ya sólo en sus ojos y en sus nervios, se arrancó: "Que no, que le tenía mucho cariño, eso sí, pero que a mí no me gustaba como hombre, vaya"... (Guerrero Zamora, 1992: 203-204)
\end{abstract}

Cegarra ya no contesta a esta tercera misiva de Miguel, con lo que se pone fin a su relación con el poeta. Tampoco tuvo suerte el poeta en esta ocasión, pues lo que él tuvo con María quedó reducido: "a una amistad que pudo alcanzar momentos de devaneo, pero que difícilmente puede calificarse de experiencia (amorosa)" (Balcells, 2009: 153)

\title{
4. La vuelta al nido del amor convencional: el miedo a la soledad
}

Ha quedado claro que Hernández no logró conquistar a la mujer que diera respuesta satisfactoria a sus deseos sexuales y a sus impulsos eróticos. Una insatisfacción en gran parte debida a su modo peculiar de concebir tanto su propia sexualidad como la de la mujer amada, pues:

En Miguel Hernández el sexo femenino es exaltado y reverenciado. Es un elemento de salvación porque en él se realiza plenamente el destino humano: por él el hombre perdura

5. En la misma respuesta al periodista J. García Martínez que la entrevistó para la sección "Domingos”, de La Verdad (Murcia) el 18.06.1978, María añade: “¿Miguel Hernández enamorado de mí?, es posible. Pero no quiero hablar del tema, para que nadie piense que busco renombre". 
hasta la eternidad, en él coexiste lo que enraíza al hombre a la tierra y lo que le lanza hacia el cielo, por él el hombre y la mujer se integran en el concierto armónico del universo. Pero hay algo en lo que este sistema difiere absolutamente de la concepción del amor en García Lorca: en Miguel Hernández se trata de una aventura individual; no es el sexo en abstracto: es el sexo de la mujer que ama. Por eso sus ideas, o mejor, sus vivencias no cuajan en un sistema coherente hasta que se superan los obstáculos que se oponían a la realización total de su experiencia personal (Mayoral, 1978: 97)

El silencio definitivo de María Cegarra echa por tierra todas sus aspiraciones el ámbito erótico-sexual. Solo y desesperado recurre a la única salida que le quedaba: recuperar la relación con su antigua novia, Josefina. Es consciente de que esta empresa no va a resultarle nada fácil, por ello - siguiendo el protocolo de la época - escribe al padre de Josefina el 1 de febrero de 1936, pidiéndole permiso para retomar el contacto con su hija. Es digno de observar cómo Hernández reconoce su culpabilidad en la ruptura, pero lo hace con especial tiento para exculparse: "los motivos por los que se interrumpieron fueron muy poca cosa de importancia", justo cuando las razones fueron de peso: sus amores con Maruja Mallo y sus intentos con María Cegarra. El poeta prefiere volver al amor "convencional", pues es así como él mismo califica a sus relaciones con Josefina, como una "amistad de mujer conmigo". Es decir, el poeta claudica a sus pretensiones sexuales y se somete al dictamen del padre de Josefina, argumentando que su ruptura con ella: "es tan solo una riña entre personas que se quieren o que se han querido bien". Se siente incapaz de decir la verdad, pues sabe que si lo hace jamás podrá recuperar a Josefina, su tabla de salvación en estos momentos tan amargos y de tanta soledad:

\footnotetext{
Yo le agradecería que usted viera si es posible hacer lo que sería mi mejor deseo que hiciera y es esto: si cree que Josefina todavía puede tenerme algún afecto y no está comprometida con ningún otro hombre, vea la manera de hablare con sencillez y de decirle si está dispuesta a continuar su amistad de mujer conmigo (Hernández, 2010: 1556)
}

Allanado el terreno, con fecha 4 de febrero de 1935, Miguel escribe a Josefina, pero lo hace con un lenguaje en el que en modo alguno se refleja la pasión y el deseo sexual que antes sintiera por Maruja Mallo, sino todo lo contrario, con expresiones claramente tradicionales: "no creas que me guía otro interés que el de enterarme si puedes continuar tus relaciones conmigo". Expresiones que le sirven para enmascarar la verdad, pues al decir "he tenido una gran experiencia 
aquí" le quiere decir a Josefina que en Madrid ha vivido experiencias amorosas que jamás podrá tener con ella, pero que a la postre de poco le han servido. Y como ahora "me encuentro muy solo", vuelvo a ti:

Josefina: No sé si sabrás por tu padre que le escribí hace varios días para saber de ti. Comprenderás que no me guía otro interés que el de enterarme si puedes continuar tus relaciones conmigo. Quiero que seas sincera, si ha dejado de pensar en mí y no te preocupa nada mi persona, dímelo si esto no es una molestia para ti. Yo, por mi parte siento que entre nosotros haya ocurrido lo que ocurrió. Estoy arrepentido y tengo toda la culpa. No creas que me guía otro interés al escribirte que volver a nuestro cariño. Te confieso que he tenido una gran experiencia aquí y que me encuentro muy solo (Hernández, 2010: 1557)

Y Miguel Hernández tuvo que aceptar la imposibilidad de conseguir el amor pasional y desinhibido de una mujer y conformarse con el cariño que podía darle Josefina. Se casaron por lo civil el 9 de marzo de 1937 y el 14 de agosto de 1942, a las puertas de la muerte, celebraron matrimonio canónico, teniendo Hernández que abdicar de su proclamado anticlericalismo y someterse a la doctrina eclesiástica:

\footnotetext{
Miguel Hernández con Josefina Manresa. En Alicante a quince de Agoto de mil novecientos cuarenta y dos ante D. Anselmo Cutayar Mauricio, Juez municipal de ejercicios anteriores en funciones, y D. Rafael Martínez Bernabeu, Secretario, se procede a transcribir el acta de matrimonio canónico: in articulo mortis, que copiado literalmente dice así [...] Reformatorio de Adultos de Alicante.

Certifico que: el cuatro de marzo de mil novecientos cuarenta y dos, se celebró en la Capilla de esta prisión, in artículo mortis el matrimonio canónico entre Miguel Hernández Gilabert, de treinta y un años de edad, natural de Orihuela, hijo de Manuel y Concepción, con doña Josefina Manresa Maruhenda de veintiséis años de edad, natural de Quesada (Jaén), hija de Manuel y de Josefa [...] (Registro Civil n ${ }^{\circ} 1$ de Alicante, 14.08.1942)
}

\section{Conclusiones}

Nos propusimos demostrar en esta colaboración que de las tres heridas, "la del amor", fue la que dejó huella más honda en Miguel Hernández, y a tenor de los argumentos, razones y testimonios aportados a lo largo de la misma, entendemos haberlo conseguido. El poeta vivió el deseo sexual como un impulso de marcado 
carácter primitivo y natural. Una realidad a la que alude Juan Cano Ballesta cuando insiste en: "la importancia que tiene en la concepción de la sexualidad de Miguel Hernández su formación natural, en el campo, viviendo desde niño la fecundación y el nacimiento de los animales" (Cano Ballesta, 1962: 38). Un impulso que se transforma en erotismo, en energía sexual que ha de proyectarse en la mujer amada, a la cual ha de tener cerca para sentir, palpar, experimentar la proximidad del ser deseado, no puede vivir alejado de ella, pues en su caso o tiene consigo al ser que quiere y canta la alegría de su unión con ella o se deprime y amarga. Una realidad que obedece a un principio vital hernandiano: "el amor es el único modo en el cual puede mostrarse el ser en su plenitud, siendo el poema el lugar de encuentro con el ausente". Y es precisamente en la poesía de Miguel Hernández donde está más claro que lo erótico y lo poético: "se superponen, porque ambos aspiran a la unidad [...] La fusión de lo masculino-fecundante y lo femenino-maternal, subyace en sus composiciones arquetípicas" (López Castro, 2003: 237-238)

En ninguna de las tres relaciones amorosas aquí analizadas logró Miguel Hernández lo que pretendía, y no solo por la incompatibilidad con el modo de entender las relaciones sexuales en la pareja, caso de Josefina Manresa, ni por el particular proceder de María Cegarra, ya que el poeta no le atrae como hombre o porque Maruja Mallo tan solo le ofrezca momentos eróticos puntuales, sino porque en ninguno de los tres casos logró vivir el sexo como él lo deseaba. Esta distancia entre lo que se desea y lo que se obtiene es lo que más dolor le causa, de tal manera que esta pena de amor insatisfecho le acompañó hasta la muerte.

\section{Bibliografía}

ACEREDA, A. (1996). Reseña a Aggor Francis Komla (1994), Eros en la poesía de Miguel Hernández. York, South Carolina, Spanish Literature Publications Company. Hispania 79 (3): 430-440.

AGGOR FRANCIS, K. (1994). Eros en la poesía de Miguel Hernández. York, South Carolina: Spanish Literature Publications Company.

BALCELLS, J. M. (1995). "De Josefina a María y de María a Maruja" en Homenaje a María Cegarra. (Ed. Santiago Delgado). Murcia: Editora Regional Murciana: 163-171.

BALCELlS, J. M. (2009). Sujetado rayo. Estudios sobre Miguel Hernández. Madrid: Devenir.

CANO BALlESTA, J. (1962). La poesía de Miguel Hernández. Madrid: Gredos. 
CEGARRA SALCEDO, M. (1935). Cristales mios. Cartagena: Levante.

CEGARRA SALCEDO, M. (1979). "Presencia de Miguel”. Tránsito. Revista de Poesía.

CELA, C. J. (2001). Memorias, entendimientos y voluntades. Madrid: EspasaCalpe.

CUENCA ABELA, D. (2015). El amor en Miguel Hernández: un impulso constante e instante. Alicante: Universidad de Alicante.

DÍEZ DE REVENGA, F. J. y M. DE PACO (2010). "Miguel Hernández en la memoria fértil de Carmen Conde". Monteagudo 15: 83-102.

FERRIS, J. L. (2004). Miguel Hernández. Pasiones, cárcel y muerte de un poeta. Madrid: Temas de Hoy.

FERRIS, J. L. (2004). "La amada plural en El rayo que no cesa" en Actas del II Congreso Internacional sobre Miguel Hernández. Orihuela-Madrid: Fundación Cultural Miguel Hernández: 49-57.

FERRIS, J. L. (2017). "Los últimos años de Miguel Hernández". Magazine Digital: 20.05.2017. <http://www.magazinedigital.com/historias/reportajes/ los-ultimos-anos-de-miguel-hernandez $>$.

FERNÁNDEZ PALMERAL, R. (2004). Simbología secreta de El rayo que no cesa. Alicante: Biblioteca Virtual Cervantes.

GÓMEZ VERA, I. (2005). "Código poético-amoroso de El rayo que no cesa" en II Congreso Internacional sobre Miguel Hernández, Orihuela-Madrid: 301-319.

GARCÍA MARTÍNEZ, J. (1978). "Entrevista a María Cegarra” en "Domingos", La Verdad, Murcia. 18.01.1978.

GRACIA, A. (2016). "Mayoral que no cesa". República de Letras 116: 19-34.

GRACIA, A. (2020). "Miguel Hernández y la poética del taco". El Cuaderno. Cuaderno Digital de Cultura, agosto, 2020. <http://www.cuadernodigital. com>.

GRANDE LARA, F.(1991). "Miguel Hernández". Cuadernos Hispanoamericanos 501: 1-20.

GUERREO ZAMORA, J. (1992). "Agenda sobre un libro reciente. Proceso a Miguel Hernández, Sumario 2001” en Estudios sobre Miguel Hernández. (Eds. F. Díez de Revenga y Mariano de Paco). Murcia: Universidad de Murcia.

HERNÁNDEZ GILABERT, M. (1958). Cancionero y romancero de ausencias. Buenos Aires: Lautaro.

HERNÁNDEZ GILABERT, M. (1978). Perito en lunas. El rayo que no cesa. Agustín Sánchez Vidal (ed.). Madrid: Alhambra. 
HERNÁNDEZ GILABERT, M. (1998). 'Cartas no 2 y 3 a María Cegarra' en José María Rubio Paredes, "La correspondencia epistolar entre Miguel Hernández y María Cegarra". Murgetana 97: 83-117.

HERNÁNDEZ GILABERT, M. (2002). El rayo que no cesa. José María Balcells (ed.). Madrid: Sial Ediciones.

HERNÁNDEZ GILABERT, M. (2010). Obra Completa, Vol. I y II. Madrid: Espasa-Clásicos.

IFACH, M. G. (1982). Vida y obra de Miguel Hernández. Barcelona: Plaza y Janes.

KOMLA AGGOR, F. (1994). Eros en la poesía de Miguel Hernández. York, South Carolina: Spanish Literature Publications Company.

LARRABIDE, A. L. (2019). "María Cegarra y Miguel Hernández. Bajo la luz de la luna y el cielo de La Unión". Monograma. Revista Iberoamericana de Cultura y Pensamiento 5: 35-53.

LÓPEZ CASTRO, A, (2003). "El impulso erótico de Miguel Hernández. Bajo la luna y el cielo de La Unión" en Actas del II Congreso Internacional sobre Miguel Hernández. Orihuela: Fundación Miguel Hernández: 227241.

MANRESA, J. (1980). Recuerdos de la viuda de Miguel Hernández. Madrid: Ediciones de la Torre.

MALLO, M. (1979). “Semblanza de Miguel Hernández” en Carpeta de Homenaje a la Revista de Occidente. Madrid: Fundación Ortega y Gasset: 5.

MALLO, M. (1989). "La vida exagerada de Maruja Mallo", por Carlos G. Santa Cecilia. El País, 23.06.1989.

MAYORAL, M. (1878). "El último rincón de Miguel Hernández” en En torno a Miguel Hernández. (Juan Cano Ballesta et al.). Madrid: Castalia: 95108.

MORALES MORENO, J. E. (2009). "La herida del amor más allá de la muerte. Análisis del poema Las tres heridas, de Miguel Hernández". Espéculo. Revista de Estudios Literarios 41.

PÉREZ ÁlVAREZ, R. (1994). "María Cegarra-Miguel Hernández: el reto de una relación sentimental incontestable". Lucerna 29: 38-39.

REGISTRO CIVIL, Copia de Acta de matrimonio canónico, Alicante, Registro Civil, ${ }^{\circ}$ 1, Sección 2, Libro 19-1: 233.

RUBIO PAREDES, J. M. (1998). "La correspondencia epistolar entre Miguel Hernández y María Cegarra". Murgetana 97: 83-117.

SÁNCHEZ VIDAL, A. (1992). Miguel Hernández desamordazado y regresado. Barcelona: Planeta. 
SÁNCHEZ VIDAL, A. (2010). "Introducción”, en Miguel Hernández, Obra Completa. Madrid: Espasa-Clásicos.

VIDAL ORTUÑO, J. M. (2010). "Sobre la amada en la poesía de Miguel Hernández". Monteagudo 15: 25-34. 